\title{
GAMBARAN SELF-COMPASSION GURU BIMBINGAN DAN KONSELING PADA JENJANG SMA NEGERI SE-DKI JAKARTA
}

\author{
Revitia Thalita Salsabila ${ }^{1}$ \\ Susi Fitri ${ }^{2}$
}

\begin{abstract}
Abstrak
Tuntutan pekerjaan guru BK yang begitu berat dan beban kerja yang tinggi membuat guru BK rentan mengalami burnout dan compassion fatigue. Permasalahan tersebut dan banyaknya hambatan guru BK dalam menjalankan profesinya akan mempengaruhi tingkat self-compassion yang dimiliki. Penelitian ini bertujuan untuk mendapatkan gambaran self-compassion yang dimiliki guru BK pada jenjang SMA Negeri se-DKI Jakarta. Penelitian ini merupakan penelitian deskriptif dengan metode survei. Sampel dalam penelitian ini terdiri dari 191 guru BK SMA Negeri se-DKI Jakarta yang dipilih dengan menggunakan teknik simple random sampling. Instrumen yang digunakan dalam penelitian ini merupakan intrumen adaptasi selfcompassion yang dikembangkan oleh Neff yang terdiri dari 26 butir pernyataan. Penelitian ini dianalisis dengan menggunakan rata-rata self-compassion dan persentase. Hasil Penelitian: Hasil penelitian menunjukkan $86 \%$ guru BK SMA Negeri se-DKI Jakarta memiliki self-compassion yang tinggi dan $14 \%$ guru BK memiliki self-compassion yang sedang dengan rata-rata skor 3.92. Hasil ini menggambarkan guru BK sudah mampu menerima diri mereka apa adanya, memahami bahwa setiap permasalahan merupakan hal yang wajar dialami oleh manusia, tidak melebih-lebihkan suatu permasalahan, dan tidak mudah terbawa suasana.
\end{abstract}

Kata Kunci: Self-compassion, Guru Bimbingan dan Konseling, DKI Jakarta

\begin{abstract}
The heavy work demands and the high workload of school counselors make them prone to burnout and compassion fatigue. The many obstacles and problems they have in carrying out their profession will affect the level of self-compassion they have. This study aims to get a profile of the self-compassion of school counselors at state high schools in DKI Jakarta. This research is a descriptive study with a survey method. The sample in this study consisted of 191 state senior high school counselors in DKI Jakarta who were selected using simple random sampling technique. The instrument used in this study is a self-compassion adaptation instrument developed by Neff, which consists of 26 statement items. This study analyzed using self-compassion average and percentage. The results showed that $86 \%$ of state senior high school school counselors in Jakarta have high self-compassion and 14\% of school counselor have moderate self-compassion with an average score of 3.92. These results illustrate that school counselors are able to accept themselves as they are, understand that every problem is a natural thing experienced by humans, do not exaggerate a problem, and are not easily carried away.
\end{abstract}

Keywords: Self-Compassion, School Counselor, DKI Jakarta

\footnotetext{
${ }^{1}$ Universitas Negeri Jakarta, revitiathalitasalsabila_1715164606@mhs.unj.ac.id

${ }^{2}$ Universitas Negeri Jakarta, susi.fitri@unj.ac.id
} 


\section{PENDAHULUAN}

Dalam mencapai tugas perkembangan peserta didik, bimbingan dan konseling memiliki peran penting dalam capaian tujuan pendidikan. Menurut Ruslan (dalam Aufa, 2014) tugas utama guru BK adalah membantu peserta didik untuk mengembangkan dan menangani kondisi kehidupan yang terganggu melalui layanan bimbingan dan konseling, baik secara individu maupun berkelompok, agar peserta didik dapat mandiri dan berkembang secara optimal dalam bidang pribadi, sosial, karir, dan belajar. Peran dan tugas ini tentu menuntut guru BK untuk mengusai kompetensi yang profesional sebagai seorang konselor.

Berdasarkan Peraturan Menteri Pendidikan dan Kebudayaan Nomor 111 Tahun 2014 Pasal 10 Ayat 2 dijelaskan bahwa beban kerja guru BK ialah 150 peserta didik setiap tahunnya. Namun, sering ditemukan bahwa jumlah peserta didik yang harus ditangani oleh seorang guru BK lebih dari 150 peserta didik, serta tuntutan yang tinggi kerap kali harus dilaksanakan dengan keterbatasan jumlah personil guru BK pada setiap sekolah dan permasalahan lainnya yang terjadi di sekolah.

Penelitian yang dilakukan oleh beberapa ahli, seperti yang dikutip oleh Missliana (2014) menunjukan bahwa profesional di bidang perawat atau helping proffesion sering mengalami kesulitan dalam mempertahankan compassion terhadap klien mereka dengan sebutan compassion fatigue. Konselor yang mengalami compassion fatigue dapat menjadi kelelahan dalam menangani konseli karena tuntutan emosional dan profesi mereka.

Menurut Keim, Olguin, Marley, \& Thieman (dalam Hunter, 2016) menyatakan bahwa umumnya konselor gagal mengenali dampak dari "penderitaan" baik secara pribadi maupun profesional. Para psikoterapis/konselor cenderung kurang merawat diri mereka. Hal ini dikarenakan adanya pengabaian sehingga kurang akan rasa kesadaran terhadap kebutuhan pribadi. Kurangnya kesadaran akan perawatan diri membuat mereka juga terkena dari efek negatif tersebut ketika berhadapan dengan klien. Para profesional kesehatan mental cenderung sulit untuk menilai diri sendiri secara akurat ketika mereka mengalami tekanan mental dan emosional.

Selain itu, banyaknya anggapan bahwa seorang konselor ahli dalam merawat diri mereka sendiri karena melihat bagaimana tingkat kepedulian konselor terhadap klien mereka. Akan tetapi menurut Cormier, Nurius, \& Osborn (dalam Hunter, 2016) menyatakan bahwa hal tersebut tidak benarbenar terjadi karena konselor hanya peduli terhadap orang lain, sehingga mereka cenderung tidak merawat diri sendiri secara memadai. Faktor yang membuat konselor sering menolak atau mengabaikan kebutuhan mereka akan perawat an diri adalah harapan yang tidak realistis, batasan hubungan antara konselor dan klien (boundery issues), dan ketidakmampuan untuk bersikap asertif. Oleh karena itu, compassion fatigue erat kaitannya dengan helping profession.

Apabila seorang konselor tidak berhatihati dalam menjalani profesinya, maka profesi tersebut dapat menjadi penyebab stres yang tidak hanya berdampak pada kesehatan pribadi, namun juga akan mempengaruhi terhadap hubungan relasi yang dimiliki (Hunter, 2016). Berdasarkan penelitian yang dilakukan oleh Cooper \& Cartwright (1994) mengenai tingkat stres pekerjaan menunjukkan profesi guru merupakan pekerjaan yang termasuk dalam kategori "very stressfull job" dan profesi konselor sekolah (guru BK) rentan mengalami stres. Hal ini dikarenakan pekerjaan konselor/guru BK terus berhadapan dengan emosionalitas yang tinggi pada saat berhadapan dengan penderitaan konseli, namun mereka harus tetap menjaga sikap profesionalitasnya (Baldwin, Barnmore, Suprina, \& Weaver, 2011).

Hasil penelitian yang dilakukan oleh Emerson, Markos, \& Lambie (dalam Yandri 
dan Juliawati, 2017) mengungkapkan 39\% konselor sekolah dan konselor komunitas sepanjang perjalanan karir mereka sempat mengalami masalah burnout dari level sedang hingga tinggi. Pernyataan tersebut diperkuat dengan penelitian yang dilakukan Susanti \& Bakhtiar (2018) mengenai gambaran burnout guru BK di Provinsi Riau yang menunjukan bahwa guru BK mengalami tekanan emosional yang tinggi karena siswa tidak dapat diatur, tidak memiliki etika yang baik dalam bersikap dan berperilaku, dan beban kerja yang berlebihan.

Dalam melaksanakan tugas sebagai guru BK, tentu akan mengalami ketidaksempurnaan, kegagalan ataupun kekurangan, sehingga Kessler (1990) menyatakan bahwa konselor sekolah rentan terhadap kejenuhan karena tingginya tingkat stres profesional terkait berbagai tuntutan pekerjaan, ambiguitas peran, konflik peran, besar jumlah siswa, dan kurangnya pengawasan. Penelitian Wilkerson \& Bellini (2006) menunjukkan sebanyak 10\%$20 \%$ konselor sekolah tidak merasa puas dengan pekerjaan mereka, sehingga rentan mengalami burnout.

Hasil penelitian tersebut menunjukan adanya korelasi dengan salah satu komponen self-compassion, yaitu common humanity. Common humanity merupakan penerimaan kesulitan, kegagalan, dan ketidaksempurnaan merupakan bagian dari hidup manusia. Konselor yang memiliki rasa tidak puas dengan hasil kerjanya dapat dikatakan memiliki isu isolation di mana ketidaksempurnaan merupakan suatu hal yang memalukan. Pengalaman-pengalaman tugas yang berat, penuh tekanan dan menimbulkan stres akan mempengaruhi seberapa kuat self-compassion yang dimiliki oleh guru BK.

Self-compassion dapat diartikan sebagai pemberi perhatian dan kebaikan diri pada saat mengalami tantangan dalam hidup, serta memiliki keyakinan bahwa kegagalan dan kekurangan yang dimiliki merupakan bagian dari kehidupan manusia (Neff, 2003a). Berdasarkan penelitian Neff (2009) mengungkapkan individu yang memiliki pengaruh positif akan mempengaruhi selfcompassion, diantaranya tingginya tingkat kepuasan hidup, emotional intelligence yang baik, kebijaksanaan, kebahagiaan, rasa optimis, inisiatif personal, tingkat depresi dan cemas yang rendah, serta minimnya perasaan takut akan kegagalan. Selfcompassion mampu memberi kekuatan emosional pada individu untuk bangkit dari perasaan kecewa ataupun frustasi, sehingga individu dapat menerima kekurangan yang dimiliki dengan memahami dan memaafkan diri, serta memiliki motivasi untuk menggali potensi yang dimiliki.

Penelitian Gilbert \& Proctor (dalam Wulandari, 2019) menemukan bahwa selfcompassion membantu menurunkan hormon stres individu. Self-compassion dapat menjadi salah satu sumber daya penanganan/coping yang berharga saat individu mengalami suatu tantangan dalam hidup. Oleh karena itu, self-compassion dapat diartikan sebagai bentuk penerimaan diri dengan berbelas kasih pada diri sendiri. Tanpa kemampuan ini individu mungkin tidak siap untuk berbelas kasih pada orang lain. Apabila seorang guru BK memiliki selfcompassion yang baik, maka kemungkinan besar guru BK akan baik kepada dirinya maupun orang lain/peserta didik. Berdasarkan fenomena di atas, penulis tertarik untuk meneliti mengenai selfcompassion yang dilihat berdasarkan tiga komponen, yakni self-kindness, mindfulness, dan common humanity pada Guru BK SMA Negeri di DKI Jakarta.

\section{Self-Compassion}

Neff (2003a) menjelaskan selfcompassion adalah bentuk perhatian dan kebaikan terhadap diri sendiri saat menghadapi berbagai kesulitan dalam hidup serta memiliki keyakinan bahwa penderitaan, kegagalan, dan kekurangan dalam diri merupakan bagian dari kehidupan. Self-compassion merupakan cara penyesuaian diri pada saat merasakan kegagalan dan kekurangan dalam hidup (Neff \& McGehee, 2010). Self-compassion merupakan strategi dalam menangani emosi 
atau perasaan negatif agar terbebaskan dari reaksi negatif akibat emosi yang dialami (Neff K. D., 2011).

Self-compassion membantu individu tidak melarikan diri atau menekan perasaan yang menyakitkan, dan meningkatkan sikap aware terhadap penderitaan yang dialami (Neff K. D., 2003b). Pendapat lainnya dikemukakan pula oleh Neff, Rude, \& Krikpatrick (2007) yang menjelaskan bahwa self-compasssion merupakan bentuk penerimaan diri yang positif terhadap aspek yang diri dan pengalaman hidup yang tidak disukai. Self-compassion menyadarkan individu bahwa tidak ada manusia yang sempurna, sehingga mampu memperlakukan diri dan orang lain dengan baik (Neff K. D., 2012). Germer (2009) menyatakan bahwa self-compassion merupakan rasa belas kasih dan bentuk penerimaan secara emosional kognitif terhadap masalah yang dialami.

Menurut Neff (2003a) self-compassion memiliki tiga komponen penting yang membentuk self-compassion, yakni selfkindness, common humanity, dan mindfulness.

Self-kindness adalah kemampuan individu dalam memahami dan menerima diri apanya tanpa memberikan penilaian negatif atau self-critism. Self-kindness membantu individu bersikap lebih hangat terhadap dirinya sendiri ketika menghadapi rasa sakit tanpa menyakiti diri sendiri. Individu yang memiliki self-kindness menyadari bahwa setiap individu tidak selalu mendapatkan semua yang diinginkannya, sehingga individu tidak mundah mengalami frustasi, stres, dan tidak malkukan self-critism. Self-kindness berbanding dengan self-judgment yang merupakan sikap merendahkan dan mengkritik diri secara berlebihan terhadap kegagalan yang dialami seseorang (Neff K. D., 2011).

Common humanity merupakan bentuk kesadaran dan penerimaan bahwa segala kegagalan, kesulitan, dan permasalahan yang terjadi merupakan bagian dari kehidupan manusia. Common humanity membantu kita melihat suatu kelemahan yang dimiliki dengan keadaan orang lain pada umumnya. Apabila individu tidak melihat gambaran secara luas dan hanya berfokus pada kekurangan yang dimiliki, maka sudut pandang individu cenderung menyempit dan merasa bahwa hanya diri sendiri yang paling menderita.

Individu yang tidak memiliki common humanity akan terfokus pada penderitaan yang dialami dan merasa tidak ada orang yang mengalami penderitaan seperti dirinya, meskipun pada kenyataannya terdapat banyak orang yang mengalami masalah dan penderitaan yang mungkin jauh lebih berat dibanding yang dirasakan oleh individu tersebut. Individu yang mempu menyadari bahwa pengalaman yang kurang menyenangkan tidak hanya dialami oleh dirinya sendiri akan membantu meningkatkan coping adaptif dan terhindar dari perasaan terisolasi (Neff K. D., 2003a).

Mindfulness merupakan konsep yang mengarah kepada kemampuan individu dalam menghadapi kenyataan dengan melihat secara jelas dan menerima segala hal yang terjadi tanpa menghakimi dan membesar-besarkan suatu kejadian. Mindfulness diperlukan oleh individu agar tidak mudah untuk teridentifikasi dengan pikiran atau perasaan negatif. Mindfulness membantu individu untuk membentuk respon yang benar dan objektif terhadap suatu permasalahan (Neff K. D., 2011). Apabila individu tidak memiliki mindfulness, maka ia cenderung melakukan over identification yang terpaku pada semua kesalahan dirinya. Over identification akan membuat individu terfokus secara berlebihan terahadap kesalahan yang diperbuat.

Menurut Neff (2011) terdapat empat faktor yang dapat mempengaruhi selfcompassion, yaitu budaya, usia, jenis kelamin, dan peran orang tua.

Neff (2011) menjelaskan bahwa selfcompassion bermanfaat dalam meningkatkan ketahanan emosional, meningkatkan harga diri dan membantu 
meningkatkan motivasi dan perkembangan diri. Germer (2009) menjelaskan bahwa selfcompassion akan membantu individu dalam proses penerimaan diri yang sesungguhnya. Kekurangan dan perasaan sakit yang dimiliki individu akan dihadapi secara optimis dan positif dengan adanya selfcompassion. Manfaat lainnya adalah membantu individu untuk berpikir secara terbuka, lebih dapat merasakan cinta dan kebaikan, meningkatkan perasaan syukur, meningkatkan rasa empati, dan membantu untuk menenangkan hati (Marotta, 2013). Neff, Rude, \& Kirkpatrick (2007) menunjukan bahwa self-compassion merupakan salah satu cara yng bijaksana dalam mengatasi emosi yang sulit dan meningkatkan kecederdasan emosional, serta meningkatkan inisiatif individu untuk menggali potensi secara optimal. Individu yang memiliki self-compassion lebih dapat menerima bahwa segala sesuatu yang diinginkannya tidak selamanya akan tercapai.

\section{METODE PENELITIAN}

Penelitian ini menggunakan penelitian deskriptif dengan metode survei. Populasi dalam penelitian ini merupakan guru bimbingan dan konseling pada jenjang SMA Negeri se-DKI Jakarta dengan jumlah sekolah sebanyak 117 SMA Negeri dan 364 guru bimbingan dan konseling. Teknik pengambilan sampel yang digunakan adalah simple random sampling dengan metode undian. Instrumen yang digunakan adalah instrument adaptasi dari self-compassion scale. Item pada instrumen yang digunakan berjumlah 26 butir dengan koefisien validitas berkisar dari $0,270-0,573$ dan koefisien reliabilitas sebesar 0,727 .

\section{HASIL PENELITIAN}

Penelitian ini dilakukan di SMA Negeri se-DKI Jakarta dengan menyebarkan instrumen daring self-compassion kepada guru BK. Jumlah sampel yang didapatkan dalam penelitian ini adalah 191 responden dengan rincian 165 guru BK perempuan dan 26 guru BK laki-laki.

\begin{tabular}{cccc}
\hline Rentang skor & $\begin{array}{c}\text { Kategori } \\
\text {-sasi }\end{array}$ & $\begin{array}{c}\text { Juml } \\
\text {-ah }\end{array}$ & $\begin{array}{c}\text { Perse } \\
\text {-ntase }\end{array}$ \\
\hline $\mathrm{X}<2,50$ & Rendah & 0 & $0 \%$ \\
$2,50 \leq \mathrm{X} \leq 3,50$ & Sedang & 27 & $14 \%$ \\
$\mathrm{X} \geq 3,50$ & Tinggi & 164 & $86 \%$
\end{tabular}

Tabel 1. Rata-rata Self-Compassion Guru BK SMA Negeri se-DKI Jakarta

Self-compassion guru BK SMA Negeri se-DKI Jakarta berada pada kategori tinggi dengan skor rata-rata sebesar 3,91 (86\%). Menurut Neff (2011) guru BK yang memiliki kategori self-compassion yang tinggi sudah mampu memberikan perhatian dan kehangatan pada diri mereka sendiri pada saat menghadapi masa-masa yang sulit. Guru BK sudah mampu menerima segala kekurangan yang dimilikinya dan tidak mengabaikan perasaan yang menyedihkan, serta mengakui kegagalan dan ketidaksempurnaan yang pernah terjadi dalam hidupnya merupakan hal yang pasti dialami oleh manusia. Guru BK juga sudah berbaik hati pada diri mereka ketika mengalami penderitaan tanpa memberikan penilaian negatif terhadap dirinya. Guru BK

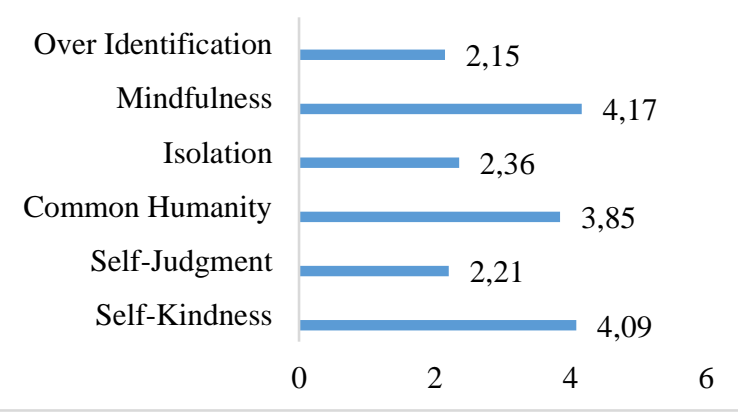

yang memiliki kategori tinggi juga tidak merasa terpisahkan dari masyarakat ketika menghadapi pengalaman yang tidak menyenangkan ataupun kegagalan. Guru BK tidak terbawa oleh perasaan yang menyedihkan atau menyakitkan dengan bersikap berlebihan. Ketika guru BK mengalami suatu hal yang menyakitkan, mereka mampu melihat hal tersebut dari berbagai perspektif dan menerima perasaan yang dialami secara terbuka. 
Menurut Hollis-Walker dan Colosimo (2011) menyatakan bahwa guru BK yang memiliki self-compassion yang tinggi memiliki kecenderungan merasakan kebahagiaan, optimisme, rasa ingin tahu, kreativitas, dan emosi positif seperti antusiasme, inspirasi, dan kegembiraan. Menurut Neff \& Dahm (2017) menyatakan guru BK dengan self-compassion tinggi akan memiliki perspektif yang luas terhadap masalah mereka dan terhindar dari perasaan terisolasi. Guru BK dengan self-compassion yang tinggi akan terbantu dalam mengambil tanggung jawab atas peran mereka terhadap kejadian negatif di masa lalu tanpa mengalami pegaruh negatif. Orang yang memiliki self-compassion yang tinggi lebih dapat berkompromi dan menyeimbangkan kebutuhan diri dan orang lain, serta kecil kemungkinannya untuk mengalami kekacauan emosional (Neff \& Yarnell, 2013).

Penelitian yang dilakukan oleh Crocker dan Canevello (dalam Neff \& Germer, 2017) menemukan bahwa self-compassion yang tinggi cenderung memiliki lebih banyak tujuan yang penuh kasih dalam suatu hubungan, artinya guru BK akan memberikan dukungan sosial dan mendorong kepercayaan interpersonal. Dengan adanya self-compassion, ketika guru BK dapat memberikan perhatian dan dukungan terhadap dirinya, maka mereka memiliki banyak sumber daya emosional yang dapat mereka berikan kepada rekannya. Berdasarkan penelitian yang dilakukan oleh Costa \& Pinto-Gouveia (dalam Neff \& Germer, 2017) selfcompassion yang tinggi membantu guru BK untuk mempertahankan keseimbangan emosi mereka. Neff \& Germer (2017) menyatakan bahwa guru BK dengan selfcompassion tinggi lebih menyadari dan menerima bahwa mereka tidak dapat selalu mencapai tujuan mereka.

Grafik 1. Rata-rata Komponen Self-Compassion

Guru BK SMA Negeri se-DKI Jakarta

Berdasarkan hasil rata-rata komponen self-compassion yang dimiliki oleh guru BK SMA Negeri se-DKI Jakarta menunjukkan bahwa item positif, yakni self-kindness $(4,09)$ dengan persentase $83,25 \%$, common humanity $(3,85)$ dengan persentase $61,78 \%$, dan mindfulness $(4,17)$ dengan persentase $86 \%$ berada pada kategori tinggi. Tiga komponen yang bernilai negatif berada pada kategori rendah dengan skor isolation $(2,36)$ dengan persentase $64,40 \%$, self-judgment $(2,21)$ dengan persentase $63,35 \%$, dan overidentification $(2,15)$ dengan persentase $77,49 \%$. Hal tersebut sesuai dengan hasil secara keseluruhan, di mana tingkat selfcompassion tinggi dengan perolehan komponen bernilai positif yang tinggi.

Berdasarkan perolehan skor keenam komponen self-compassion, terlihat bahwa mindfulness memiliki skor paling tinggi dibandingkan yang lain, yakni sebesar 4,17. Menurut Neff (2011) mengatakan bahwa mindfulness membawa individu kembali ke saat sekarang dan menyeimbangkan kesadaran untuk membentuk fondasi selfcompassion.

\begin{tabular}{ccc}
\hline Rentang Usia & $\begin{array}{c}\text { Skor Rata- } \\
\text { rata }\end{array}$ & Kategori \\
\hline $\begin{array}{c}\text { 20-30 Tahun } \\
\text { (early-aged })\end{array}$ & 4,16 & Tinggi \\
$\begin{array}{c}\text { 31-60 tahun } \\
\text { (middle-aged })\end{array}$ & 4,17 & Tinggi \\
\hline
\end{tabular}

Tabel 2. Rata-rata mindfulness guru BK SMA

Negeri se-DKI Jakarta berdasarkan usia

Adanya mindfulness akan membantu guru BK untuk melihat situasi yang lebih luas dan membantu memastikan bahwa mereka tidak perlu menderita. Selain itu, menurut psikologi Buddis (dalam HollisWalker \& Colosimo, 2011) menyatakan bahwa menggabungkan tingkat compassion dan mindfulness yang tinggi berhubungan dengan tingkat kebahagiaan yang lebih tinggi.

Komponen mindfulness yang tinggi juga membantu guru BK dalam proses konseling, seperti yang dinyatakan oleh Fulton (2016) bahwa konselor (guru BK) dengan mindfulness yang tinggi memiliki kecemasan yang lebih rendah dan keyakinan konseling yang lebih besar, yang meningkatkan kapasitas mereka untuk 
berempati. Lebih lanjut, Fulton (2016) menyatakan terdapat kemungkinan jika mindfulness guru BK dapat menjadi model keterbukaan terhadap pengalaman untuk konseli/klien mereka, di mana mindfulness dan self-compassion yang tinggi membantu konselor untuk tidak menghindari suatu pengalaman (experimential avoidance).

\begin{tabular}{ccc}
\hline Rentang Usia & $\begin{array}{c}\text { Skor Rata- } \\
\text { rata }\end{array}$ & Kategori \\
\hline $\begin{array}{c}\text { 20-30 Tahun } \\
\text { (early-aged })\end{array}$ & 3,83 & Tinggi \\
$\begin{array}{c}\text { 31-60 tahun } \\
\text { (middle-aged })\end{array}$ & 3,92 & Tinggi \\
\hline
\end{tabular}

Tabel 3. Rata-rata Self-Compassion Guru BK

SMA Negeri se-DKI Jakarta Berdasarkan Usia

Perolehan skor guru BK SMA Negeri se-DKI Jakarta pada rentang usia 20-30 tahun 3,83 dan rentang usia 31-60 tahun sebesar 3,92 dan keduanya berada pada kategori tinggi. Hasil tersebut menunjukkan adanya peningkatan skor self-compassion pada usia 31-60 tahun (middle-aged) sebesar 0,09 . Hasil self-compassion yang tinggi dipengaruhi oleh usia guru BK, seperti penelitian yang dilakukan oleh Phillips (2019) menyatakan bahwa self-compassion meningkat seiring bertambahnya usia. Dalam Neff \& Pommnier (2012) menjelaskan bahwa perkembangan dapat memainkan peran terhadap sejauh mana individu peduli dengan penderitaan diri sendiri dan orang lain. Seiring bertambahnya usia, kepedulian terhadap diri sendiri dan orang lain akan terus berkembang sebagai hasil dari kematangan emosi dan pemahaman akan kondisi manusia.

Self-compassion mungkin penting bagi individu yang berada pada middle-aged, seperti penelitian yang dilakukan oleh Ryff (dalam Soodeok, Guenyoung, Jae-Won, \& Eunjoo, 2016) yang mengeksplorasi komponen kesejahteraan bagi orang dewasa middle-aged bahwa self-acceptance merupakan salah satu dari tiga kondisi kebahagiaan untuk pertengahan masa dewasa. Lebih lanjut, Soodeok, Guenyoung, Jae-Won, \& Eunjoo (2016) menemukan bahwa self-compassion memainkan peran pentng dalam menjalani kehidupan yang makmur secara psikologis untuk orang dewasa yang berada pada middle-aged. Selain itu, self-compassion memiliki peran dalam mengurangi aspek penuaan yang tidak diinginkan, seperti para lansia yang memiliki self-compassion memiliki pemikiran positif tentang penuaan (Soodeok, Guenyoung, Jae-Won, \& Eunjoo, 2016).

Menurut Neff (2011) menyatakan bahwa individu dalam tahapan integrity lebih dapat menerima kondiri dirinya, sehingga level self-compassion individu akan meningkat. Krisis ego integrity vs despair terjadi pada masa dewasa ketika seseorang merenungkan kematian dan mengevaluasi kehidupan yang telah mereka jalani. Resolusi tahap yang berhasil akan menghasilkan integritas ego, yakni gabungan antara kebijaksaaan, keutuhan, integrasi, dan penerimaan dalam kaitannya dengan pengalaman kehidupan masa lalu seseorang (Phillip \& Ferguson, 2012). Pernyataan tersebut didukung oleh penelitian yang dilakukan oleh Bratt \& Fagerström (2019) yang menyatakan bahwa beberapa orang dewasa yang lebih tua menyebutkan secara spontan bahwa mereka lebih menerima diri mereka sendiri dan kekurangan mereka daripada ketika mereka masih muda.

Pernyataan tersebut menunjukkan bahwa tingkat self-compassion yang tinggi sejalan dengan tahap integritas ego Erikson yang terdiri dari penerimaan masa lalu. Dalam penelitian Bratt \& Fagerström (2019) juga menemukan bahwa usia yang lebih tinggi dikaitkan dengan common humanity yang lebih tinggi dan self-judgment yang lebih rendah dapat berarti bahwa selfcompassion terus meningkat dengan usia.

Menurut Neff, Hsieh, \& Dejitthirat (dalam Neff \& Germer, 2017) menyatakan bahwa tingginya self-compassion yang dimiliki individu akan menurunkan perasaan takut akan kegagalan. Neely, Schallert, Mohammed, \& Roberts (dalam Neff \& Germer, 2017) menjelaskan lebih lanjut, di mana ketika guru BK mengalami kegagalan, maka mereka akan mencobanya kembali. Menurut Machkintosh, Power, 
Schwannauer, \& Chan (2017) guru BK dengan self-compassion tinggi dapat menerima kesalahan dan kekurangan diri, serta memiliki harga diri yang tinggi. Guru BK dapat menerima ketidaksempurnaan diri sebagai suatu hal yang wajar dan memiliki cara pandang mengenai manusia pasti pernah membuat suatu kesalahan. Neff (2003a) menjelaskan bahwa guru BK dengan self-compassion tinggi akan cenderung bersikap baik terhadap diri mereka sendiri seperti orang lain. Selain itu, ketika guru BK memiliki kepuasaan compassion yang tinggi, mereka dapat melakukan compassion for others dan meningkatkan kesejahteraan, serta meminimalisir terjadinya burnout (Beaumont E. , Durkin, Martin, \& Carson, 2016).

Penelitian yang dilakukan oleh Durkin, Beaumont, Martin \& Carson (2015) menunjukkan apabila guru BK menikmati pekerjaan mereka dapat meningkatkan kesejahteraan yang lebih baik, tingkat selfcompassion yang tinggi, burnout dan compassion fatigue yang lebih rendah. Menurut Boellinghaus (dalam Durkin, Beaumont, Martin \& Carson, 2015) menyaktakan bahwa mengembangkan selfcompassion dengan belajar menenangkan diri di saat stres berpotensi mengurangi resiko terkena compassion fatigue dan burnout, serta meningkatkan kesejahteraan pribadi. Sejalan dengan penelitian yang dilakukan Leary (dalam Durkin, Beaumont, Martin \& Carson, 2015) yang mengidentifikasi bahwa individu yang menunjukkan self-compassion ketika mengalami penderitaan cenderung tidak mengalami stres atau masalah kesehatan mental lainnya. Individu dengan ketahanan emosional yang tinggi cenderung kurang memperhatikan kegagalan dan fokus pada strategi coping yang lebih efektif di saat masa-masa sulit.

Penelitian Chisima, Mizuno, Sugawara, \& Miyagawa (2018) menemukan bahwa self-compassion memiliki kaitan dengan cara coping stres yang dirasakan individu. Self-compassion dapat mengurangi perasaan tertekan dan memberi kemmpuan untuk mengontrol tekanan karena individu menyadari bahwa hambatan dalam sebuah masalah merupakan suatu hal yang umum. Jika guru BK mengalami tekanan dalam menjalankan profesinya, self-compassion membantu mereka untuk melihat sudut pandang yang luas daripada terfokus pada hambatan atau masalah yang terjadi. Dengan demikian, tingginya coping stress guru BK akan meningkatkan pula self-compassion yang dimiliki.

Walaupun penelitian ini menunjukkan rata-rata guru BK SMA Negeri se-DKI Jakarta berada pada kategori tinggi, guru BK yang masih berada pada kategori sedang masih perlu ditingkatkan. Menurut Neff (2011) individu yang berada pada kategori sedang masih memiliki kecenderungan untuk melakukan self-critism, merasa terisolasi dari lingkungan, dan melebihlebihkan masalah. Albertson, Neff, \& DillShackleford (2014) menemukan bahwa mendengarkan poadcast dengan aktif selama tiga minggu mengenai meditasi dan self-compassion dapat meningkatkan selfcompassion dan mempengaruhi citra diri individu, khususnya pada perempuan yang cenderung melakukan self-critism.

Shapira \& Mongrain (2010) menunjukan bahwa mempraktikkan selfcompassion dalam waktu singkat menghasilkan perubahan kesehatan mental berkelanjutan. Dalam penelitian tersebut, individu yang menulis sebuah surat belas kasih (compassionate letter) pada diri mereka sendiri selama satu kali seminggu mengenai peristiwa yang menyedihkan yang baru terjadi menunjukkan pengurangan signifikan dalam depresi hingga tiga bulan dan peningkatan yang signifikan dalam kebahagiaan hingga enam bulan.

Neff \& Germer (2017) juga mengembangkan program pelatihan yang bernama Mindful Self-Compassion (MSC) selama delapan minggu untuk meningkatkan self-compassion. Program tersebut terdiri dari loving-kindness, affectionate breathing, self-compassionate latter, dan lain sebagainya menunjukan $43 \%$ peningkatan 
dalam self-compassion, compassion for others, perhatian dan kepuasan hidup, serta penurunan yang signifikan dalam depresi, kecemasan, stres, dan emotional avoidance.

Dalam penelitian ini tentu tidak terlepas dari adanya keterbatasan yang dialami. Dalam menganalisis hasil penelitian yang dilakukan, peneliti mengalami hambatan dalam mencari referensi/jurnal yang berkaitan dengan penelitian. Hal ini dikarenakan penelitian yang dilakukan masih termasuk baru dalam membahas mengenai gambaran yang dimiliki selfcompassion guru BK di Indonesia, khususnya di DKI Jakarta. Kelemahan dan keterbatasan lainnya adalah penelitian ini hanya dilakukan di SMA Negeri se-DKI Jakarta, sehingga hasil dari penelitian ini tidak dapat digeneralisasikan pada guru BK di SMA/MA swasta di Provinsi DKI Jakarta dan SMK Negeri/Swasta yang berada di DKI Jakarta.

\section{KESIMPULAN}

Berdasarkan hasil penelitian selfcompassion guru BK di SMA Negeri se-DKI Jakarta, dapat disimpulkan bahwa selfcompassion guru BK sudah sangat baik dengan perolehan skor sebesar 3,91. Hal ini terlihat dari sebagian besar self-compassion guru BK berada pada kategori tinggi dengan persentase sebesar 86\% (164 responden). Hasil tersebut menggambarkan bahwa guru BK sudah mampu untuk peduli terhadap diri sendiri, mampu memahami diri sendiri dengan baik, mampu menerima kekurangan dan perasaan yang dimiliki, serta mengakui kegagalan dan ketidaksempurnaan yang pernah terjadi dalam hidupnya merupakan hal yang wajar dialami oleh manusia. Guru BK yang memiliki kategori tinggi juga tidak merasa terpisahkan dari masyarakat ketika menghadapi pengalaman yang tidak menyenangkan ataupun kegagalan. Guru BK tidak mudah terbawa oleh situasi dan bersikap secara wajar terhadap suatu kejadian. Ketika mengalami kekecewaan, guru BK mampu menjaga emosi agar tetap stabil dan menerima perasaan mereka secara terbuka.
Hasil penelitian berdasarkan komponen self-compassion, perolehan skor tertinggi berada pada komponen mindfulness dengan perolehan skor sebesar 4,17 dengan persentase sebesar $82,68 \%$. Jika dilihat berdasarkan usia, perolehan skor mindfulness pada rentang usia 20-30 tahun sebesar 4,16 dan rentang usia 31-60 tahun sebesar 4,17. Berdasarkan rentang usia, skor mindfulness yang dimilki guru BK termasuk dalam kategori tinggi yang menunjukkan bahwa guru BK dapat menjaga emosi secara stabil ketika mengalami kekecawaan, mampu melihat kejadian menyakitkan dari berbagai perspektif, dan ketika merasa terpuruk, mereka mampu menerima secara terbuka perasaan tersebut.

Selain itu, terdapat dua komponen lain berada pada kategori tinggi (self-kindness dan common humanity) dan tiga komponen lain berada pada kategori rendah, yakni selfjudgment, isolation, dan over-identification. Komponen self-kindness memperoleh skor sebesar 4,09 dengan persentase sebesar $83,25 \%$. Common humanity memperoleh skor sebesar 3,85 dengan persentase sebesar 61,78\%. Self-judgment memeperoleh skor sebesar 2,21 dengan persentase sebesar $63,35 \%$. Isolation memperoleh skor sebesar 2,36 dengan persentase sebesar $64,40 \%$ dan over-identification memperoleh skor sebesar 2,15 dengan persentase sebesar 77,49\%.

Kemudian berdasarkan rentang usia, perolehan skor self-compassion pada rentang usia 20-30 tahun sebesar 3,83 dan rentang usia 31-60 tahun sebesar 3,92. Skor pada kedua rentang usia tersebut termasuk dalam kategori tinggi dan terjadi peningkatan sebesar 0,09 pada rentang usia 31-60 tahun.

Berdasarkan hasil penelitian, diharapkan penelitian ini dapat menjadi bahan pertimbangan bagi guru BK untuk meningkatkan self-compassion yang dimiliki guna membantu gutu BK ketika menghadapi permasalahan ataupun tekanan yang terjadi dalam kehidupan dan pekerjaan. Bagi peneliti selanjutnya yang berminat untuk mengkaji fenomena dengan tema sejenis diharapkan dapat 
mempertimbangkan beberapa hal yang membuat penelitian selanjutnya menjadi lebih baik, seperti memperluas ruang lingkup populasi untuk memberikan insight baru terhadap gambaran self-compassion guru bimbingan dan konseling dan meningkatkan kualitas alat ukur agar lebih valid dan reliabelitas dalam melihat variable yang diteliti. Serta, mengkaji faktor yang mempengaruhi self-compassion yang tidak dibahas dalam penelitian ini, seperti faktor jenis kelamin, budaya dan peran orang tua. Diharapkan juga penelitian selanjutnya dapat melakukan penelitian secara lebih mendalam dalam mengkaji self-compassion yang dimiliki oleh guru BK.

\section{DAFTAR PUSTAKA}

Albertson, E., \& Dill-Shackleford, K. (2014). Self-Compassion and Body Dissafaction in Women: A Random Controlled Trial of A Brief Meditation Intervention. Mindfulness, 8(1), 1-11.

Aufa, A. (2014). Upaya Preventif Guru Bimbingan dan Konseling Terhadap Terjadinya Burnout. Jurnal Hisbah, 11(1), 1-15.

Baldwin, K., Barnmore, C., Suprina, J., \& Weaver, A. (2011). Burnout Syndrome in Licensed Mental Health Counselors and Registered Mental Health Counselor Interns: A Pilot Study. American Counseling Association Conference (pp. 1-12). Alexandria: American Counseling Association.

Beaumont, E., Durkin, M., Martin, C. H., \& Carson, J. (2016). A Pilot Study Exploring The Relationship Between Self-Compassion, SelfJudgment, Self-Kindness, Compassion, Professional Quality of Life and Wellbeing among UK Community Nurses. Nurse Education Today, 109-114.

Beaumont, E., Durkin, M., Martin, C., \& Carson, J. (2015). Compassion for
Others, Self-Compassion, Quality of Life and Mental Well-Being Measures and Their Association With Compassion Fatigue and Burnout in Student Widwives: A Quantitative Survey. Midwifery, 34, 239-244. doi:http://dx.doi.org/10.1016/j.mid w.2015.11.002

Bratt, A., \& Fagerström, C. (2019). Selfcompassion in old age: confirmatory factor analysis of the 6-factor model and the internal consistency of the Self-compassion scale-short form. Aging \& Mental Health, 24(4), 642-648. doi:https://doi.org/10.1080/136078 63.2019.1569588

Chishima, Y., Mizuno, M., Sugawara, D., \& Miyagawa, Y. (2018). The Influence of Self-Compassion on Cognitive Appraisals and Coping With Stressful Events. Mindfulness 9, 1907-1915. doi:https://doi.org/10.1007/s12671018-0933-0

Cooper, C., \& Cartwright, S. (1994). StressManagement Interventions in the Workplace: Stress Counselling and Stress Audits. British Journal of Guidance and Counselling, 22(1), 65-73.

Fulton, C. L. (2016). Mindfulness, SelfCompassion, and Counselor Characteristics and Session Variable. Journal of Mental Health Counseling, 38(4), 360-374. doi:doi: $10.17744 /$ mehc.38.4.06

Germer, C. K. (2009). The Mindful Path To Self-Compassion Freeing Yourself From Destructive Thoughts and Emotions. New York: The Guilford Press.

Hollis-Walker, L., \& Colosimo, K. (2011). Mindfulness, Self-Compassion, and Happiness in Non-Meditators: A Theoretical and Empirical Examination. Personality and Individual, 50(2), 222-227. 
Hunter, S. T. (2016). Beyond the Breaking Point: Examining the Pieces of Counselor Burnout, Compassion Fatigue, and Secondhand Depression. (G. R, Walz, \& J. C. Bluer, Eds.) Vistas Online, pp. 116.

Kessler, K. D. (1990). Burnout: A Multimodal Approach to Assessment and Resolution. Journal of Elementary School Guidance and Counseling, 22(2), 303-311.

Machkintosh, K., Power, K., Schwannauer, M., \& Chan, S. Y. (2017). The Relationship Between SelfCompassion, Attachment and Interpersonal Problems in Clinical Patients With Mixed Anxiety and Depression and Emotional Distress. Mindfulness, 72(6), 1-11. doi:https://doi.org/10.1007/s12671017-0835-6

Marotta, J. (2013). 50Mindful Steps to SelfEsteem: Everyday Practice for Culvating Self-Acceptance and Self-Compassion. Oakland: New Harbinger Publications.

Missiliana. (2014). Self-Compassion dan Compassion for Others Pada Mahasiswa Fakultas Psikologi UK. Maranatha. Bandung': Universitas Kristen Maranatha.

Neff, K. D. (2003a). The Development and Validation of Scale to Measure Self-Compassion. Self and Identity, 223-250.

Neff, K. D. (2003b). Self-Compassion: An Alternative Conceptualization of A Healthy Attitude Toward Oneself. Self and Identity, 2, 85-101.

Neff, K. D. (2009). Self-Compassion. In M. Leary, \& R. Hoyle, Handbook of Individual Differences in Social Behavior (pp. 561-573). New York: Guildford Press.

Neff, K. D. (2011). Self-Compassion: Stop Beating Yourself Up and Leave Insecurity Behind. London: Hodder and Stoughton.
Neff, K. D. (2012). The Science of SelfCompassion. In C. Germer, \& R. Siegel, Compassion and Wisdom in Psychotherapy (pp. 79-92). New York: Guilford Press.

Neff, K. D., \& Dahm, K. A. (2017). SelfCompassion: What it is, what it does, and how it relates to mindfulness. B. A. Gaudiano, Major themes in mental health. Mindfulness: Nonclinical applications of mindfulness: Adaptations for school, work, sports, health, and general wellbeing (pp. 495-517). New YorkSpringer: Routledge/Taylor \& Francis Group.

Neff, K. D., \& Pommier, E. (2012). The Relationship Between SelfCompassion and Other-focused Concern among College Undergraduates, Community Adults, and Practicing Meditators. Self and Identity, 1-17. doi:http://dx.doi.org/10.1080/15298 868.2011.649546

Neff, K., \& Germer, C. (2017). SelfCompassion and Psychological Well-Being (J. Doty (Ed) ed.). Oxford: Oxford University Press.

Neff, K., \& McGehee, P. (2010). SelfCompassion and Psychological Resilience Among Adolescents and Young Adoults. Self and Identity, 9(3), 225-240.

Neff, K., \& Yarnell, L. M. (2013). SelfCompassion, Interpersonal Conflict Resolutions, and Well-being. Self and Identity, 12(1), 146-159.

Neff, K., Rude, S., \& Kirkpatrick, K. (2007). An Examination of SelfCompassion in Relation To Positive Psychological Functioning and Personality Traits. Journal of Research in Personality, 908-916.

Phillip, W., \& Ferguson, S. (2012). Self-

Compassion: A Resource for Positive Aging. Journals of Gerontology Series B: Psychological Sciences and Social 
Sciences, 68(4), 529-539.

doi:10.1093/geronb/gbs091

Phillips, W. J. (2019). Self-Compassion

Mindsets: The Components of The

Self-Compassion Scale Operate as

A Balaced System Within

Individuals. Curr Psychol.

doi:https://doi.org/10.1007/s12144-

019-00452-1

Shapira, L., \& Mongrain, M. (2010). The

Benefits of Self-Compassion and

Optimism Exercises for Individuals

Vulnerable to Depression. The

Journal of Positive Psychology, 5, 377-389.

Soodeok, H., Guenyoung, K., Jae-Won, Y., \& Eunjoo, Y. (2016). The

Moderating Effects of Age on the

Relationships of Self-Compassion,

Self-Esteem, and Mental Health.

The Japanese Psychological

Research, 58(2), 194-205.

doi:10.1111/jpr.12109

Susanti, R., \& Bakhtiar, N. (2018).

Kejenuhan di Kalangan Guru

Bimbingan dan Konselig di SMAN

Provinsi Riau. Educational

Guidance and Counseling

Development Journal, 2(1), 92-104.

Wilkerson, K., \& Bellini, J. (2006).

Interpersonal and Organizational

Factors Associatedwith Burnout

Among School Counselors. Journal

of Counseling and Development, 84(4), 84-90.

Wulandari, H. (2019). Peran Self

Compassion dan Regulasi Emosi

Terhadap Stres Pada Guru

Penderita Diabetes Mellitus Tipe 2

yang Menjalani Pengobatan Rawat

Jalan di RSUD Kabupaten

Purbalingga. 2019: Magister

Psikologi Pascasarjana Universitas

Ahmad Dahlan.

Yandri, H., \& Juliawati, D. (2017). Burnout

Pada Guru/Konselor Sekolah.

Konselor, 6(2), 61-65.

doi:10.24036/02017627561-0-00 


\section{Lampiran}

\section{Instrumen Penelitian Gambaran Self-Compassion Guru BK SMA Negeri se-DKI Jakarta}

Identitas Responden

Nama

Unit Kerja

Usia

Dengan ini, saya menyatakan bahwa saya bersedia untuk mengisi kuesioner penelitian ini dengan sukarela dan tidak dibawah paksaan atau tekanan dari pihak tertentu, demi membantu pelaksanaan penelitian. Semua jawaban yang saya berikan adalah murni merupakan gambaran dari diri saya dan bukan berdasarkan pada pandangan masyarakat secara umum. Saya mengizinkan penggunaan jawaban atau tanggapan yang saya berikan tersebut sebagai data guna memperlancar penelitian ilmiah ini.

Petunjuk:

Bacalah setiap pernyataan dengan seksama dan pilih satu jawaban yang paling sesuai dengan diri Bapak/Ibu. Pikirkan bagaimana Bapak/Ibu paling sering melihat diri sendiri, merasa, atau berlaku (tingkah laku) dalam sehari-hari.

Instrumen ini memiliki 26 butir pernyataan dengan 5 alternatif jawaban dan semua jawaban bernilai benar.

Nilai setiap item dalam instrumen ini berada pada skala dari 1-5 dengan keterangan sebagai berikut.

$1=$ tidak pernah

$2=$ jarang

3 = kadang-kadang

$4=$ sering

$5=$ selalu

\begin{tabular}{|c|c|c|c|c|c|c|}
\hline No & Butir Pernyataan & 1 & 2 & 3 & 4 & 5 \\
\hline 1 & $\begin{array}{l}\text { Saya tidak bisa menerima dan kritis terhadap kelemahan- } \\
\text { kelemahan saya }\end{array}$ & & & & & \\
\hline 2 & $\begin{array}{l}\text { Ketika kondisi saya memburuk, saya cenderung memikirkan } \\
\text { dan hanya berfokus pada hal-hal yang berjalan buruk dalam } \\
\text { hidup saya }\end{array}$ & & & & & \\
\hline 3 & $\begin{array}{l}\text { Ketika kondisi saya memburuk, saya melihat kesulitan-kesulitan } \\
\text { yang saya alami sebagai bagian dari kehidupan yang dialami } \\
\text { semua orang }\end{array}$ & & & & & \\
\hline 4 & $\begin{array}{l}\text { Ketika saya memikirkan kekurangan saya, hal tersebut membuat } \\
\text { saya merasa terpisahkan oleh kehidupan sosial }\end{array}$ & & & & & \\
\hline
\end{tabular}




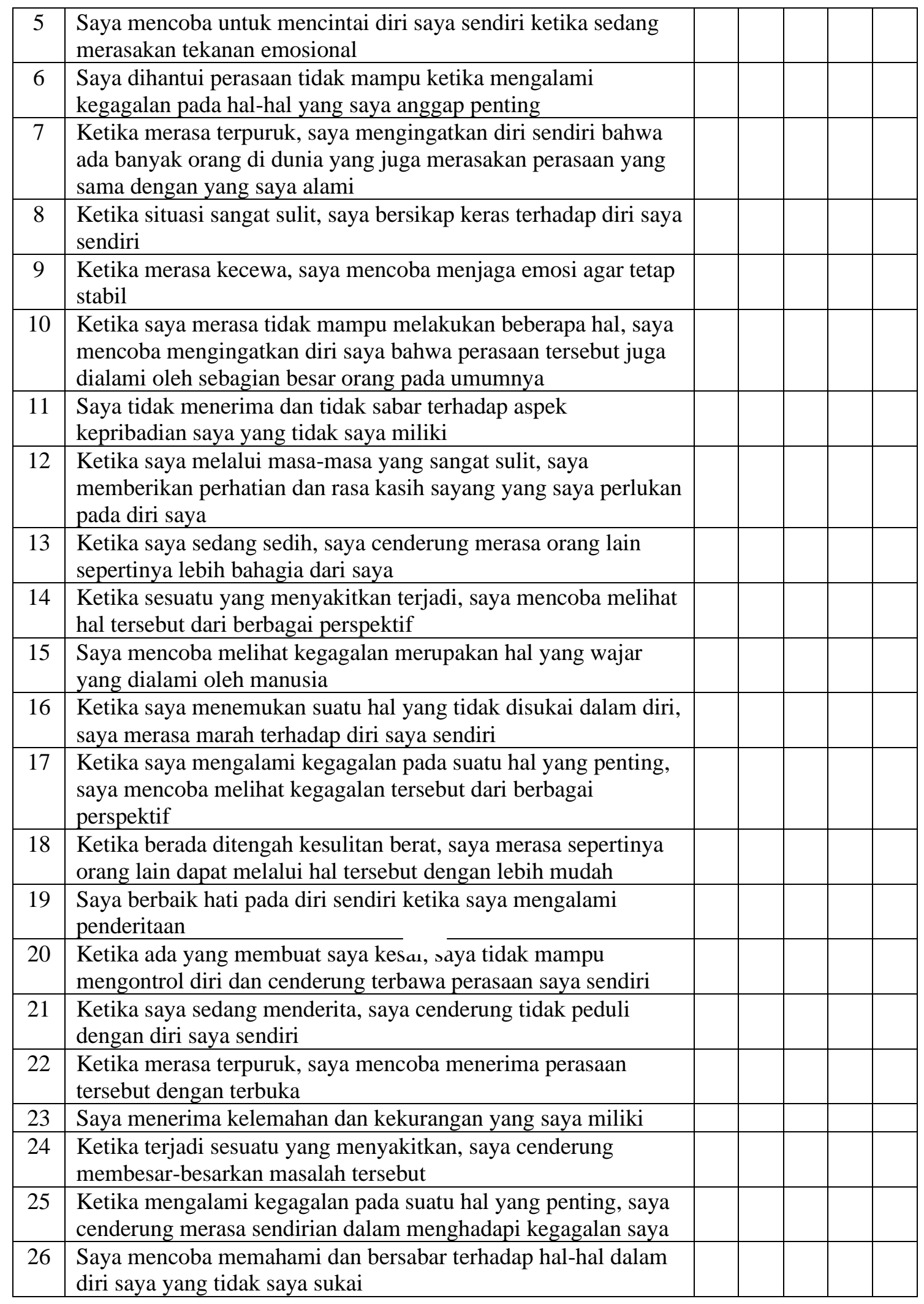

